\title{
Targeting neddylation induces DNA damage and checkpoint activation and sensitizes chronic lymphocytic leukemia B cells to alkylating agents
}

\author{
C Paiva ${ }^{1,5}$, JC Godbersen ${ }^{2,5}$, A Berger ${ }^{3}$, JR Brown $^{4}$ and AV Danilov ${ }^{*, 1}$
}

Microenvironment-mediated upregulation of the B-cell receptor (BCR) and nuclear factor- $\kappa B$ (NF- $\kappa B$ ) signaling in CLL cells resident in the lymph node and bone marrow promotes apoptosis evasion and clonal expansion. We recently reported that MLN4924 (pevonedistat), an investigational agent that inhibits the NEDD8-activating enzyme (NAE), abrogates stromal-mediated NF- $\kappa$ B pathway activity and CLL cell survival. However, the NAE pathway also assists degradation of multiple other substrates. MLN4924 has been shown to induce DNA damage and cell cycle arrest, but the importance of this mechanism in primary neoplastic $B$ cells has not been studied. Here we mimicked the lymph node microenvironment using CD40 ligand (CD40L)-expressing stroma and interleukin-21 (IL-21) to find that inducing proliferation of the primary CLL cells conferred enhanced sensitivity to NAE inhibition. Treatment of the CD40-stimulated CLL cells with MLN4924 resulted in deregulation of Cdt1, a DNA replication licensing factor, and cell cycle inhibitors p21 and p27. This led to DNA damage, checkpoint activation and G2 arrest. Alkylating agents bendamustine and chlorambucil enhanced MLN4924-mediated DNA damage and apoptosis. These events were more prominent in cells stimulated with IL-21 compared with CD40L alone, indicating that, following NAE inhibition, the culture conditions were able to direct CLL cell fate from an NF- $\kappa B$ inhibition to a Cdt1 induction program. Our data provide insight into the biological consequences of targeting NAE in CLL and serves as further rationale for studying the clinical activity of MLN4924 in CLL, particularly in combination with alkylating agents.

Cell Death and Disease (2015) 6, e1807; doi:10.1038/cddis.2015.161; published online 9 July 2015

The ubiquitin-proteasome system ensures timely destruction of intracellular proteins. In the past decade, protein degradation has become a pharmacologic target: proteasome inhibitors (e.g., bortezomib) are currently being used in therapy of plasma and B-cell neoplasms. Inhibiting the ubiquitination process upstream of the proteasome represents a promising alternative approach. In this regard, ubiquitin-like modifiers (Ubl) such as NEDD8, ISG15 (interferon-stimulated gene 15), and SUMO (small ubiquitin-like modifier) regulate diverse cellular processes, depending on the exact $\mathrm{Ubl}$ and substrate involved. One such Ubl, NEDD8, modulates CullinRING E3 ubiquitin ligase (CRL) activity through covalent modification, neddylation. ${ }^{1}$

Chronic lymphocytic leukemia (CLL) B cells are highly dependent on cell-cell interactions in the lymph node and bone marrow microenvironment. ${ }^{2}$ Stromal-mediated upregulation of B-cell receptor (BCR) and nuclear factor- $k \mathrm{~B}$ (NF-kB) signaling in CLL cells resident in these niches ensures apoptosis evasion and promotes proliferation and clonal expansion. ${ }^{3}$ We recently reported that MLN4924 (pevonedistat), an investigational inhibitor of the NEDD8-activating enzyme (NAE), successfully abrogates NF-KB pathway activity, CLL cell survival and chemoresistance in an in vitro co-culture model that mimics the lymph node microenvironment. ${ }^{4} \mathrm{NAE}$ adenylates NEDD8 at its C-terminus and allows its transfer to a specific cysteine within NAE, thus initiating a process of neddylation. Active NEDD8 is then transferred to the cysteine of the ubiquitin-conjugating enzyme (E2) specific for the pathway (Ubc12), and is finally conjugated to the CRLs. ${ }^{5}$ CRLs are responsible for ubiquitination and degradation of their substrate proteins. NAE-NEDD8 interaction is disrupted when a covalent adduct is formed between NEDD8 and MLN4924. ${ }^{6}$ Ultimately, this prevents ubiqitination of $\mathrm{CRL}$ target proteins, extending their half-life, thereby increasing levels of inhibitor of NF-KB (IKB), a negative pathway modulator. ${ }^{6-8}$ However, CRLs process a variety of proteins that, in addition to signal transduction (IKBa, DEPTOR, $\beta$-catenin, hypoxia-inducible factor-1 $\alpha$ ) and apoptosis (NOXA, Bim $\mathrm{EL}_{\mathrm{L}}$ ), are important regulators of cell cycle and DNA replication (e.g., p21 ${ }^{\mathrm{Cip} 1}$, p27 ${ }^{\mathrm{Kip} 1}$, Wee1, Cyclin D1 and Cdt1). ${ }^{9-14}$ Because of the diversity of CRL target substrates, the biological consequences of their inhibition are

\footnotetext{
${ }^{1}$ Knight Cancer Institute, Oregon Health and Science University, Portland, OR, USA; ${ }^{2}$ Geisel School of Medicine at Dartmouth, Hanover, NH, USA; ${ }^{3}$ Millennium Pharmaceuticals, Inc., a wholly owned subsidiary of Takeda Pharmaceutical Company Ltd, Cambridge, MA, USA and ${ }^{4}$ Medical Oncology, Dana-Farber Cancer Institute, Boston, MA, USA

*Corresponding author: AV Danilov, OHSU Knight Cancer Institute, Oregon Health and Science University, 3181 SW Sam Jackson Park Road, Portland, OR 97239 , USA. Tel: +1 503494 4875; Fax: +1 503494 3688; E-mail: danilov@ohsu.edu

${ }^{5}$ The first two authors contributed equally to this work.

Abbreviations: CD40L, CD40 ligand; Cdt1, chromatin licensing and DNA replication factor 1; IL-21, interleukin-21; CpG-ODN, CpG oligodeoxynucleotide; $\gamma \mathrm{H} 2 \mathrm{AX}$, phospho-histone 2A.X; Chk, checkpoint kinase; Cdc25A, cell division cycle 25A; CDK, cyclin-dependent kinase; NBS1, Nijmegen breakage syndrome 1; Bcl2, B-cell lymphoma 2; PARP, poly-ADP ribose polymerase; $\mathrm{Rb}$, retinoblastoma

Received 02.3.15; revised 06.5.15; accepted 12.5.15; Edited by H-U Simon
} 
tissue dependent. In adherent solid tumor cell lines, inhibition of neddylation resulted in characteristic deregulation of cell cycle with DNA re-replication, checkpoint activation and cell cycle arrest, thought to be secondary to stabilization of the replication-licensing protein Cdt1 (chromatin licensing and DNA replication factor 1 ) and cyclin-dependent kinase (CDK) inhibitor p21 ${ }^{\text {Cip1 }} .^{11,15-17}$ However, the importance of this mechanism in primary neoplastic B cells has not been studied. Here we determined that, under the conditions promoting cell replication and growth, MLN4924 induces checkpoint activation and cell cycle arrest in primary CLL B -cells. This mechanism complements abrogation of NF- $\kappa \mathrm{B}$ pathway activity to induce apoptosis in CLL.

\section{Results}

CLL cells induced to proliferate exhibit greater sensitivity to MLN4924. Growth restriction and apoptosis following inhibition of NEDD8-activating enzyme in solid tumor cell lines occurs because of DNA re-replication and damage, yet it is not known whether this occurs in primary lymphoid tumors. CLL cells obtained from peripheral blood rest in $\mathrm{G}_{0} / \mathrm{G}_{1}$ and undergo spontaneous apoptosis when devoid of their supportive microenvironment. Hence, to mimic the lymph node microenvironment and induce CLL cell proliferation in vitro, we deployed co-cultures with CD40 ligand (CD40L)-expressing stroma, as previously described by us and others. ${ }^{4,18}$ Under these conditions, $<1 \%$ of cells entered $\mathrm{S}$ phase as early as $24 \mathrm{~h}$, as evidenced by EdU incorporation (Figure 1a). We then further induced CLL cell proliferation by means of CpG oligodeoxynucleotide (CpG-ODN), a Toll-like receptor agonist, ${ }^{19}$ or interleukin-21 (IL-21). Whereas IL-21 induced apoptosis of the CLL cells outside of their protective niche, ${ }^{20}$ CD40L-stimulated CLL cells may be induced to proliferate in its presence. ${ }^{21}$ Despite intersample variation at earlier time points, up to $20 \%$ of CLL cells proliferated after a continuous $72 \mathrm{~h}$ exposure to either $1.5 \mu \mathrm{M}$ CpG-ODN or $25 \mathrm{ng} / \mathrm{ml}$ IL-21 (Figure 1a).

To determine whether NAE inhibition influences survival of the CLL cells that are forced to enter cell cycle, cells were cocultured with CD40L-expressing stroma for $72 \mathrm{~h}$ with or without IL-21, and treated with MLN4924 for 8 or $24 \mathrm{~h}$. IL-21 enhanced CLL cell sensitivity to MLN4924. A total of $63.7 \% \pm 2.6$ and $44.4 \pm 5.4 \%$ underwent apoptosis after a $24 \mathrm{~h}$ treatment with $1 \mu \mathrm{M}$ MLN4924 in the presence or not of IL-21, correspondingly $(P=0.00004$; Figure 1b). Similar findings were observed when CpG-ODN was employed (Supplementary Figure S1A). In contrast, CD3 ${ }^{+}$and CD19 ${ }^{+}$ cells isolated from healthy donors exhibited minimal sensitivity to MLN4924 under the same conditions (Supplementary Figure S2A). Thus, CLL cells treated with either IL-21 or CpG-ODN demonstrated enhanced sensitivity to MLN4924.

\footnotetext{
MLN4924 deregulates Cdt1 and induces DNA damage and checkpoint activation in CD40L-stimulated CLL cells. We supposed that the proliferative CLL cell fraction was sensitized to MLN4924. As re-replication is a wellestablished consequence of NAE inhibition and results from deregulation of Cdt1 function, we then studied Cdt1 in CLL.
}

Indeed, early accumulation of Cdt1 occurred in a dosedependent manner in the CD40L-stimulated cells treated with MLN4924 (Figure 2a). Cdt1 was also overexpressed in cells stimulated with IL-21 or CpG-ODN (Figure 2a and Supplementary Figure S1B). In contrast, Cdt1 levels remained undetectable in CLL cells cultured off stroma (Supplementary Figure S3). Because IL-21 was more reliable at inducing proliferation than CpG-ODN, we used it in our subsequent experiments.

As overexpression of Cdt1 has been shown to induce DNA re-replication followed by head-to-tail collision of replication forks, ${ }^{22}$ we tested whether checkpoint activation occurred in CLL cells under these conditions. Indeed, cells treated with MLN4924 exhibited an early rise in markers of DNA damage, such as phosphorylation of $\mathrm{H}_{2} \mathrm{AX}$ (phospho-histone 2A.X) and replication protein $A$ (RPA), and these events preceded caspase cleavage of poly-ADP ribose polymerase (PARP; Figure 2a). These changes were evident at an earlier time point $(4 \mathrm{~h})$ in cells co-stimulated with IL-21, likely indicating a higher fraction of cells progressing through cell cycle and thus susceptible to DNA damage. Indeed, we determined that CLL cells undergoing proliferation (as evidenced by expression of Ki-67) succumbed to DNA damage (Figure $2 b$ ). In contrast, we observed no evidence of Cdt1 accumulation and DNA damage in normal PBMCs (Supplementary Figure S2B). Furthermore, DNA damage induced checkpoint activation in CLL cells, and this was particularly evident in IL-21-treated cells. Interestingly, both checkpoint kinases 1 and 2 (Chk1 and Chk2) were phosphorylated in the presence of MLN4924, further suggesting that targeting NAE induced activity of both ATM (ataxia telangiectasia mutated) and ATR (ataxia telangiectasia and Rad3 related) activity in CLL cells (Figure 2a). To confirm the role of Cdt1 in checkpoint activation, we performed genetic knockdown of Cdt1 in CD40L/IL-21-stimulated CLL cells and treated them with MLN4924. This manipulation resulted in reduced DNA damage and Chk1 activation as evidenced by immunoblotting and immunostaining, as well as decreased apoptosis (Figure 3 and Supplementary Figure S4).

Degradation of a dual-specificity phosphatase cell division cycle 25A (Cdc25A) involved in G2/S transition is also CRL dependent. ${ }^{23}$ Chk1 phosphorylates and inactivates Cdc25A, thereby inhibiting CDK1 activity and cell cycle progression. Treatment with MLN4924 led to increased Cdc25A levels, whereas the levels of Wee1, another CRL target and a negative CDK1 regulator, did not consistently change in CLL cells in the presence of MLN4924 (Figure 2a).

We further analyzed whether Cdt1 accumulation and checkpoint activation in response to NAE inhibition was accompanied by cell cycle deregulation in CD40L-stimulated CLL cells. As expected, stimulation with IL-21 led to an increase in the number of cells in $S$ and $G_{2} / M$ phases of cell cycle (Figure 4a; $P=0.0001$ and $P=0.0003$, correspondingly). Furthermore, treatment with MLN4924 caused a pronounced accumulation of cells in $\mathrm{G}_{2} / \mathrm{M}$ phases of cell cycle; an $\mathrm{S}$ phase increase was observed in CD40L-only-stimulated cells (Figure 4a). Although CLL cells demonstrated a dosedependent increase in $>4 \mathrm{~N}$ DNA content, such extensive overreplication was less pronounced in primary lymphoid cells than previously reported in cell lines treated with MLN4924 (Figure 4b). ${ }^{15}$ 
a
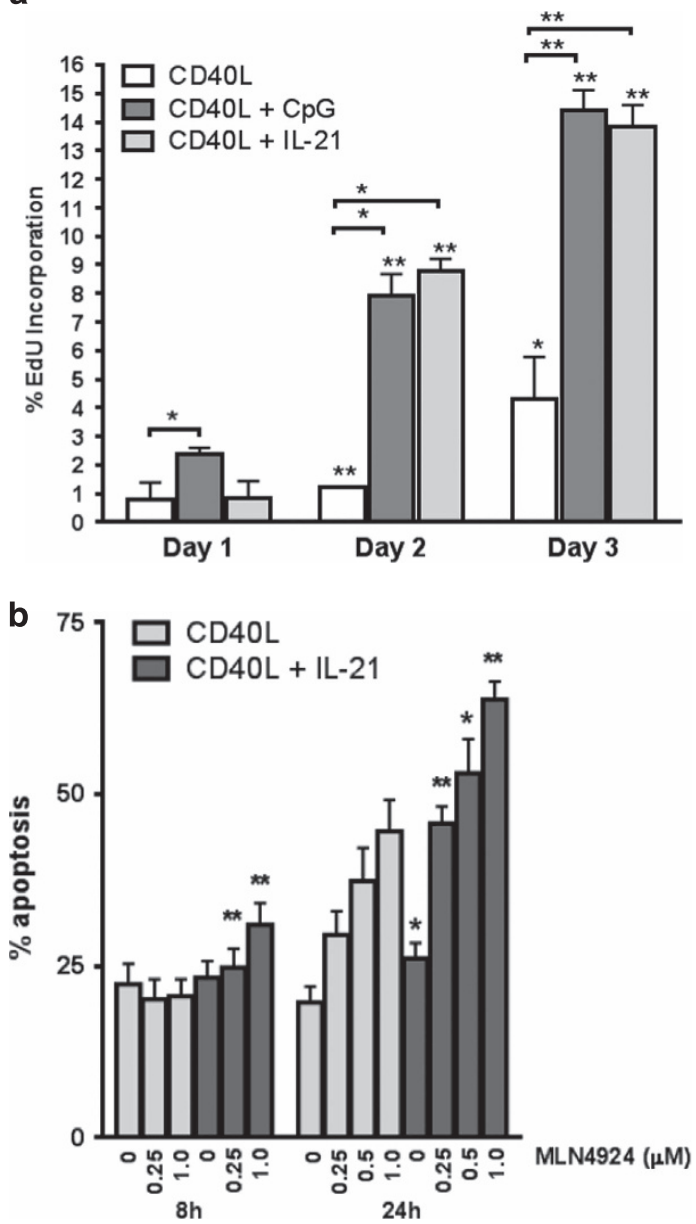
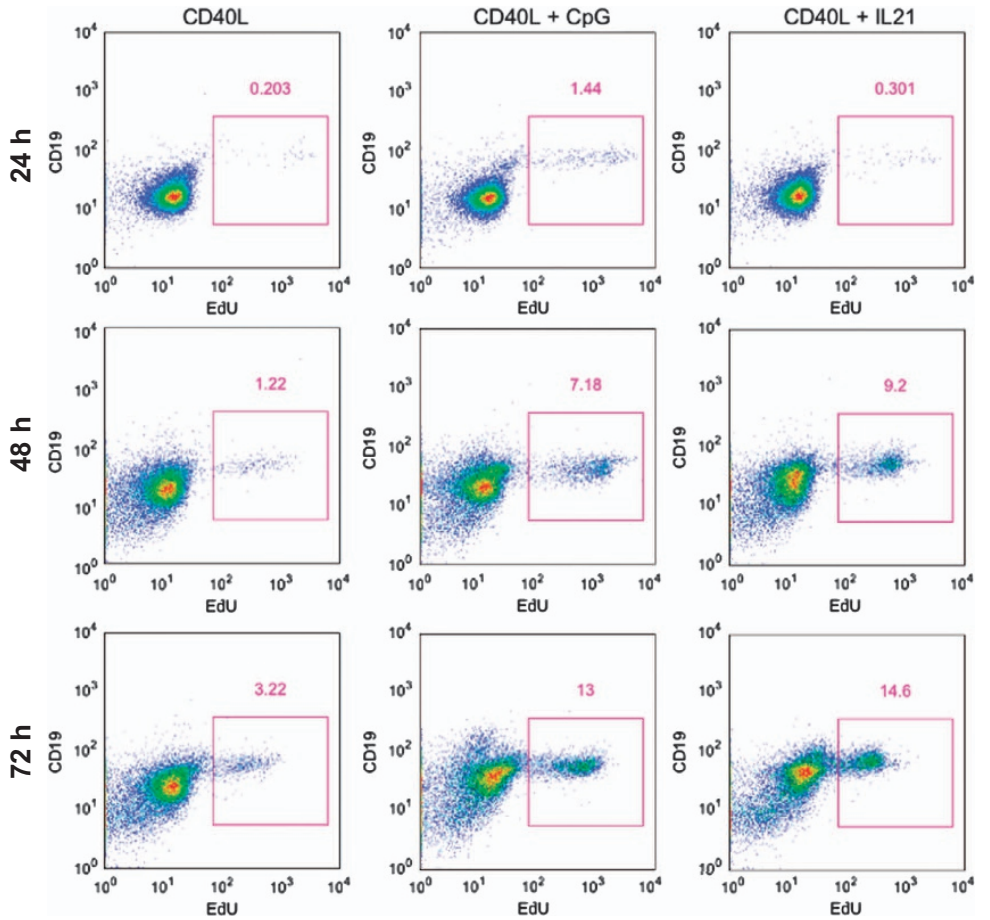

Figure $1 \mathrm{CLL}$ cells induced to proliferate are sensitized to MLN4924. (a) CLL cells $(N=4)$ were co-cultured with CD40L-expressing stroma for up to $72 \mathrm{~h}$ in the presence or not of $25 \mathrm{ng} / \mathrm{ml}$ IL-21 or $1.5 \mu \mathrm{M} \mathrm{CpG-ODN}$. Cells were collected daily, labeled with 5-ethynyl-2'-deoxyuridine (EdU) and assayed by flow cytometry. Data are mean \pm S.E. A representative image is shown. (b) CLL cells were co-cultured with CD40L-expressing stroma in the presence or not of $25 \mathrm{ng} / \mathrm{ml} \mathrm{IL}-21$. After $72 \mathrm{~h}$, cells were treated with 0.25-1 $\mu \mathrm{M}$ MLN4924 or vehicle control for the indicated time intervals. Apoptosis within the CD19+ subset of cells $(N=10)$ was determined by Annexin V and 7-AAD staining. ${ }^{*} P<0.05$ and ${ }^{* *} P<0.01$ compared with $\mathrm{CD} 40 \mathrm{~L}$ only

The above data strongly suggested that Cdt1-mediated DNA re-replication and checkpoint activation contribute to the mechanism of action of MLN4924 in proliferating CLL cells. Therefore, we interrogated CLL cells resident in different phases of cell cycle for early evidence of apoptosis. Indeed, $21.4 \pm 5.1 \%$ of cells in $\mathrm{G}_{2} / \mathrm{M}$ phases of cell cycle demonstrated caspase-3 cleavage after an 8-h exposure to $1 \mu \mathrm{M}$ MLN4924 as compared with $10.9 \pm 2.6 \%$ of cells resting in $\mathrm{G}_{0} / \mathrm{G}_{1}$ (Figure $4 \mathrm{c}$ ). Thus, targeting NAE in primary CLL cells induces aberrant Cdt1 accumulation with ensuing DNA damage, cell cycle deregulation and accelerated apoptosis of cells induced to proliferate.

NAE inhibition deregulates endogenous CDK inhibitors in CLL cells. A number of other relevant proteins regulate cell cycle and are targets of CRL-mediated ubiquitination. p2 $7^{\text {Kip1 }}$ and p21 ${ }^{\text {Cip1 }}$ are endogenous CDK inhibitors that bind to Cyclin-CDK2/CDK1/CDK4/6 complexes and thus regulate cell cycle progression at $\mathrm{G}_{1} / \mathrm{S}$ checkpoint. Importantly, p21 ${ }^{\text {Cip1 }}$ also has a defined role in $G_{2}$ checkpoint sustenance after DNA damage. ${ }^{24}$ Hence, we evaluated whether NAE inhibition deregulates endogenous CDK inhibitors, thus enhancing apoptosis in CLL. We found that baseline $\mathrm{p} 27^{\mathrm{Kip} 1}$ and $\mathrm{p} 21^{\mathrm{Cip} 1}$ protein levels were low in CD40Lstimulated cells, and additional stimulation with IL-21 had no effect (Figure 5a). Following NAE inhibition, both endogenous CDK inhibitors were upregulated in CD40Lstimulated CLL cells, but not in cells cultured off stroma (Figure 5a and Supplementary Figure S3).

As CIP/KIP CDK inhibitors promote dephosphorylated state of pocket proteins (retinoblastoma $(\mathrm{Rb}), \mathrm{p} 107$ and p130) thereby exercising control over $\mathrm{G}_{1} / \mathrm{S}$ transition, we evaluated whether they might play a role in $\mathrm{G}_{1} / \mathrm{S}$ checkpoint activation in CLL cells treated with MLN4924. Rb protein was hyperphosphorylated in cells stimulated with IL-21, possibly indicating the fact that a larger fraction of cells progressed through cell cycle under these conditions (Figure 5a). We did not observe a change in $\mathrm{Rb}$ phosphorylation in CD40L-stimulated cells at early time points of incubation with the drug (4 and $8 \mathrm{~h}$ ). Meanwhile, late hypophosphorylation of $\mathrm{Rb}$ at $24 \mathrm{~h}$ could be a result of cell apoptosis (Figure 5a). Finally, knockdown of either $\mathrm{p} 27^{\mathrm{Kip} 1}$ or $\mathrm{p} 21^{\mathrm{Cip} 1}$ had no effect on $\mathrm{yH} 2 \mathrm{AX}$, Chk1 phosphorylation or cell apoptosis (Figure 5b). Thus, we conclude 
that the endogenous CDK inhibitors play little role in MLN4924mediated induction of DNA damage and apoptosis in CLL.

MLN4924 sensitizes CLL cells to the alkylating agents. We further explored the interaction between MLN4924 and the chemotherapy agents commonly used in treatment of CLL, bendamustine and chlorambucil. Although these alkylating agents induce DNA crosslinking and DNA damage at all phases of the cell cycle, they are most toxic to cells that progress through $\mathrm{S}$ phase. As targeting NAE in CLL induces DNA damage, we hypothesized that MLN4924 might sensitize CLL cells to the alkylating agents through this mechanism, where DNA damage might overwhelm DNA repair mechanisms.
Although CD40L-stimulated CLL cells were resistant to either bendamustine or chlorambucil alone, treatment with MLN4924 resensitized them to both agents (Figure 6a). Furthermore, the cooperative effect of bendamustine and MLN4924 was enhanced in the presence of IL-21 (Figure 6b). Although treatment with bendamustine alone led to minimal DNA damage in the CLL cells cultured on the CD40L-expressing stroma, both single- and double-strand DNA damage was enhanced in the presence of both drugs, evidenced by phosphorylation of RPA, H2AX and p-NBS1 (Figure 6c). Although re-replication and $\mathrm{G}_{2}$ arrest described above were evident in the presence of MLN4924 and, to a lesser extent, bendamustine, the drug combination-mediated DNA damage was not due to an increase in either of these events (Figure 6d).

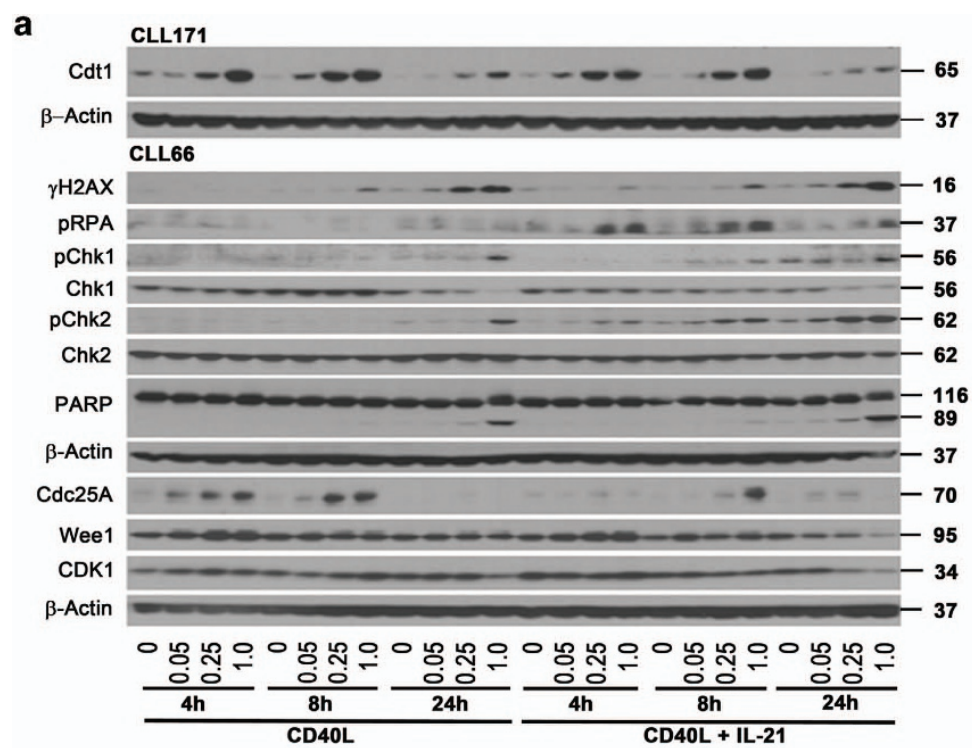

b
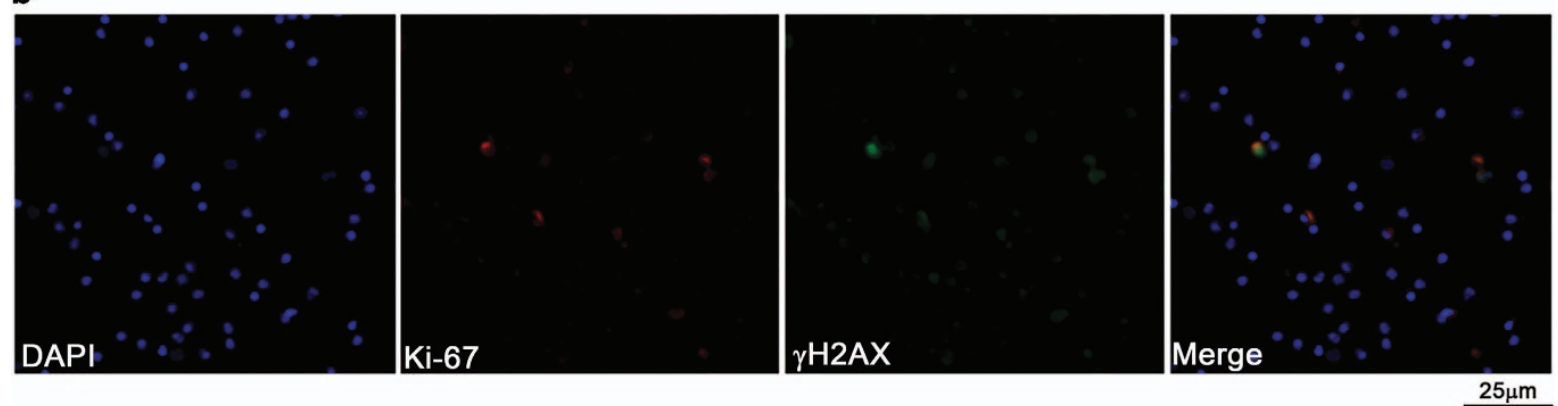

Figure 2 CLL cells undergo DNA damage and checkpoint activation in response to treatment with MLN4924. (a) CLL cells were co-cultured with CD40L-expressing stroma in the presence or absence of $25 \mathrm{ng} / \mathrm{ml} \mathrm{IL-21}$ for $72 \mathrm{~h}$. Thereafter, cells were treated with $0.05-1 \mu \mathrm{M}$ MLN4924 or vehicle control, collected at the indicated time points and subjected to immunoblotting. Images representative of four independent experiments are shown. (b) CLL cells $(N=4)$ were co-cultured as above with $25 \mathrm{ng} / \mathrm{ml} \mathrm{IL}-21 \mathrm{followed} \mathrm{by} \mathrm{a} 6$-h incubation with $1 \mu \mathrm{M}$ MLN4924. Cells were immunostained with $\gamma \mathrm{H}_{2} \mathrm{AX}$ and Ki-67 antibodies. Nuclei were counterstained with 4,6-diamino-2-phenylindole. A representative case is shown

Figure 3 NAE inhibition-induced DNA damage and apoptosis are Cdt1 dependent. CLL cells were transfected with the individual siRNAs against Cdt1 or control siRNA using Amaxa program X-005. Immediately after nucleofection, cells were cultured in the presence of $25 \mathrm{ng} / \mathrm{ml} \mathrm{IL-21} \mathrm{for} 72 \mathrm{~h}$. Thereafter, cells were treated with MLN4924 or vehicle control. (a and $\mathbf{b}$ ) Upon 24-h incubation with $0.5 \mu \mathrm{M}$ MLN4924, proteins were lysed and cells were subjected to immunoblotting. Images representative of four independent experiments are shown. Apoptosis within the $\mathrm{CD} 19^{+}$subset of cells $(N=10)$ was determined by Annexin V and 7-AAD staining; results were normalized to vehicle-treated control. (c and d) Upon 6-h incubation with $1 \mu \mathrm{M}$ MLN4924 $(N=6)$, cells were immunostained with $\gamma \mathrm{H}_{2} \mathrm{AX}$ antibodies. A representative case is shown. Six high-power fields per sample were scored for expression of $\gamma \mathrm{H}_{2} \mathrm{AX}$ as described in the Materials and Methods. Data are mean $\pm \mathrm{S}$.E. ${ }^{*} P<0.01$ compared with control conditions 

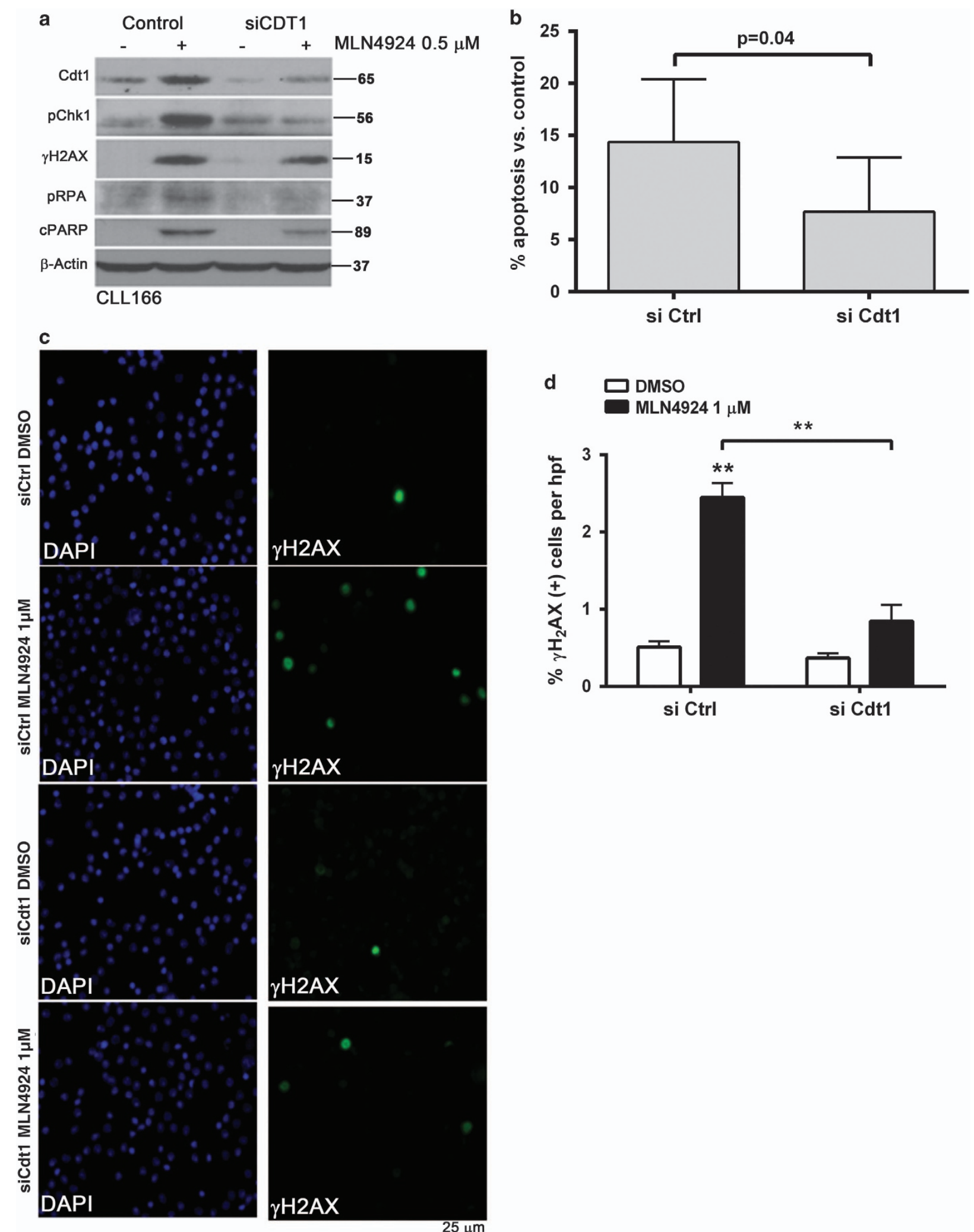
As we have previously demonstrated that MLN4924 induces BH3-only proteins BIM and NOXA in CLL cells, ${ }^{4}$ and bendamustine induces NOXA in non-Hodgkin's lymphoma cells, ${ }^{25}$ we investigated whether the cooperative effect of these two drugs was due to enhanced upregulation of these pro-apoptotic B-cell lymphoma 2 (BCL2) family members. However, whereas incubation with MLN4924 led to a dramatic induction of NOXA and BIM in CLL cells, bendamustine had no effect, suggesting that this mechanism did not contribute to toxicity of this drug combination (Figure 6e).

Finally, we have previously shown that inhibiting NAE effectively induced apoptosis of CLL cells harboring high-risk features, including del(17p). ${ }^{4}$ Such patients represent an ongoing unmet clinical need. ${ }^{26}$ To determine whether a combination of bendamustine and MLN4924 may represent a promising therapeutic approach in this disease category, we tested cells obtained from patients with del(17p) CLL. Although bendamustine has also shown preclinical promise in high-risk CLL, ${ }^{27}$ we did not observe a cooperative effect between the two drugs (Figure 6f). This is consistent with lack of clinical efficacy of bendamustine in CLL with del(17p), ${ }^{28}$ and likely indicates that its cytotoxicity is dependent on functional p53.

\section{Discussion}

A preclinical study by Milhollen et al..$^{8}$ provided initial rationale to target neddylation in B-cell malignancies. In line with the context-specific role of neddylation, the cytotoxic effects of MLN4924 in diffuse large B-cell lymphoma (DLBCL) cells were dependent on the cell of origin. In germinal center B-cell-like (GC) DLBCL cells, targeting NAE resulted in accumulation of Cdt1, DNA re-replication and cell cycle arrest in S phase, reminiscent of the consequences of NAE inhibition in adherent human colorectal carcinoma HCT116 cells. ${ }^{15,16}$ In contrast, in activated B-cell-like (ABC) DLBCL cells, abrogation of transcriptional activity of NF- $\mathrm{B}$ was the dominant event that preceded apoptosis. $^{8}$

We have recently shown that targeting NAE in CLL cells neutralizes NF- $\kappa \mathrm{B}$ through disrupted ubiquitination of $\mathrm{I}_{\kappa} \mathrm{B}$ (canonical pathway) and diminished processing of p100 to p52 (noncanonical pathway), as in ABC DLBCL. ${ }^{4}$ Treatment with MLN4924 shifted the balance of BCL2 family members toward the pro-apoptotic $\mathrm{BH}$-only proteins, with dramatic upregulation of BIM and NOXA, ${ }^{4}$ an event of high importance in CLL cells whose survival is highly dependent on the anti-apoptotic BCL2 family members. ${ }^{29}$ Disruption of NF- $\kappa \mathrm{B}$ activity as a consequence of NAE inhibition is therefore an important mechanism of MLN4924-induced apoptosis in activated CLL cells that received stimulation with CD40L or BAFF (B-cell activating factor) in the stromal niche. ${ }^{30,31}$ However, niche-resident CLL cells are exposed to a variety of stimuli beyond those necessary for NF$\kappa \mathrm{B}$ activation and demonstrate decreased apoptotic priming, that is, higher threshold of sensitivity to apoptosis via intrinsic mitochondrial pathway, ${ }^{18}$ and hence upregulation of the proapoptotic $\mathrm{BH} 3-$ only proteins may be less deadly.

Although proliferation of the CLL cells in peripheral circulation is negligible, ${ }^{32}$ clone renewal may be substantial, ${ }^{33}$ suggesting that cells found in the CLL proliferation centers may be susceptible to MLN4924-mediated cell cycle deregulation. Here we extend our earlier findings to ascertain that Cdt1 accumulated in CD40L-activated CLL cells treated with MLN4924. Ensuing re-replication ${ }^{22}$ leads to DNA damage and checkpoint activation, contributing to MLN4924 toxicity in CLL. As S-phase cells demonstrate enhanced susceptibility to MLN4924-induced DNA re-replication, ${ }^{15}$ we stimulated CLL cells with $\mathrm{IL}-21,{ }^{21}$ significantly expanding proliferative cell fraction, and thus were able to sensitize CLL cells to MLN4924. A larger proportion of cells showed evidence of DNA damage and cell cycle arrest when coincubated with IL-21, potentially relevant to cells induced to proliferate by their microenvironment in vivo. Importantly, our data also implicate that changes in culture conditions can switch the cell fate from an NF- $\mathrm{BB}$ inhibition program to a Cdt1 induction program when NAE is inhibited, as both phenomena are observed on the same cell background (primary malignant B cell).

We observed that CLL cells predominantly arrested in $G_{2}$ upon treatment with MLN4924. In contrast, some DLBCL cells underwent S-phase arrest. $^{8}$ Interestingly, a recent study suggested that lower concentrations of MLN4924 induce $\mathrm{G}_{2}$ arrest, whereas saturating doses of the drug cause a delay in S-phase progression. ${ }^{23}$ Genetic knockdowns of Cdt2, a conserved component of $\mathrm{CRL} 4^{\mathrm{Cdt} 2}$ E3 ligase that targets Cdt1 for degradation, or of geminin, a negative regulator of Cdt1, lead to $G_{2}$ arrest. $^{34,35}$ Thus, different means of inducing re-replication may result in activation of either intra-S or G2 checkpoints. It is also possible that the S-phase arrest observed in DLBCL cells could also have resulted from disrupted ubiquitination of the CDK inhibitors p21 $1^{\text {Cip } 1}$ and p27 ${ }^{\text {Kip1 }}$. In the CLL cells, these proteins accumulated but did not alter cell fate in response to MLN4924, although their role in G2/S transition has not been fully explored in this study.

Earlier findings suggested that CLL cells possess DNA damage repair ability that is highly variable between individual samples. ${ }^{36,37}$ However, understanding of DNA repair mechanisms in CLL is limited as it was only studied in resting cells ex vivo. In our work we demonstrate that CLL cells, when forced to enter cell cycle in stromal co-cultures, are able to activate DNA damage response. Generation of single- and double-stranded DNA breaks, as evident by RPA phosphorylation, $\gamma \mathrm{H} 2-\mathrm{AX}$ in response to treatment with MLN4924 and phospho-NBS1 (predominantly in response to bendamustine) resulted in activation of Chk1 and Chk2 kinases. Although bendamustine was minimally toxic in stromal co-cultures, checkpoint activation was not sufficient to repair DNA damage induced by the NAE inhibitor. High expression of endogenous BCL2 may inhibit ribonucleotide reductase activity, thereby reducing the pool of intracellular dNTPs. ${ }^{38}$ CLL cells are

Figure 4 NAE inhibition induces cell cycle deregulation in CLL. (a and $\mathbf{b}$ ) CLL cells were co-cultured with CD40L-expressing stroma in the presence or absence of $25 \mathrm{ng} / \mathrm{ml}$ IL-21 for $72 \mathrm{~h}$. Cells were treated with the indicated doses of MLN4924 or vehicle control for $24 \mathrm{~h}$ and assayed for cell cycle profiling as described in the Materials and Methods. A representative image is shown. (c) $C L L$ cells $(N=6)$ were cultured as above and assayed for apoptosis (caspase-3 cleavage) within the resting $\left(G_{0} / G_{1}\right)$ and cell proliferative fractions $\left(G_{2} / M\right)$ after an $8 \mathrm{~h}$ exposure to MLN4924. Data are mean \pm S.E. ${ }^{*} P<0.05$ and ${ }^{* *} P<0.01$ compared with untreated control 
a
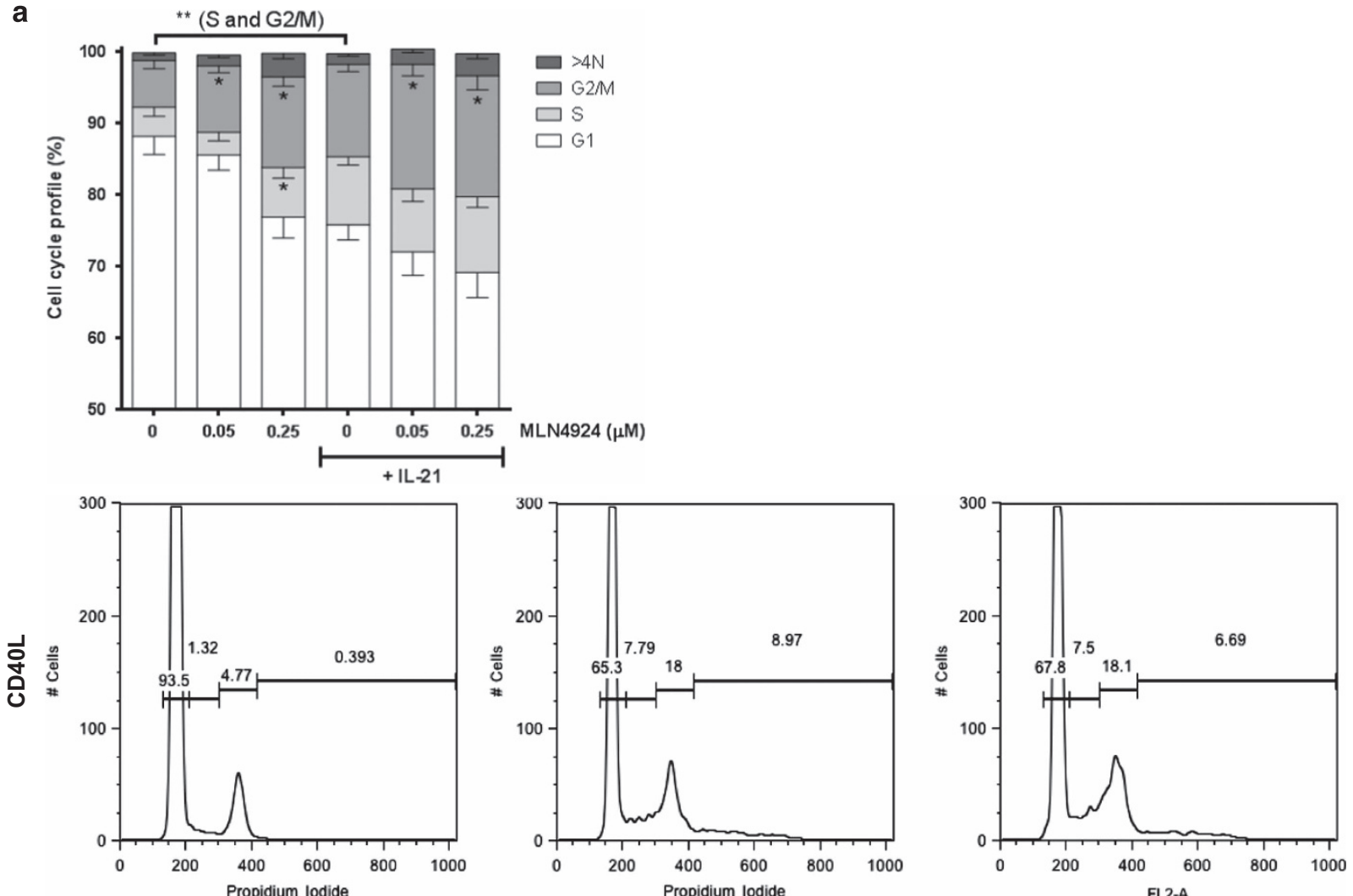

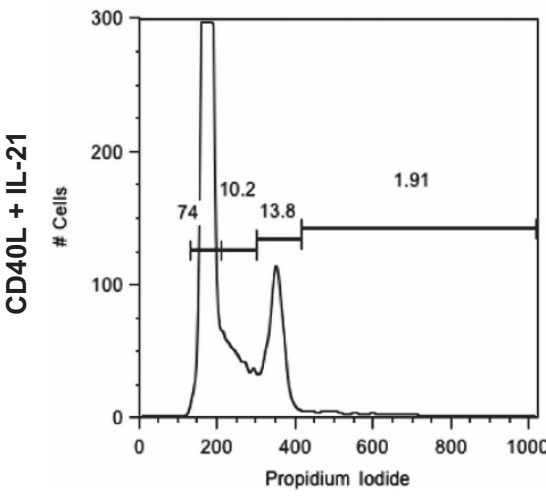

0

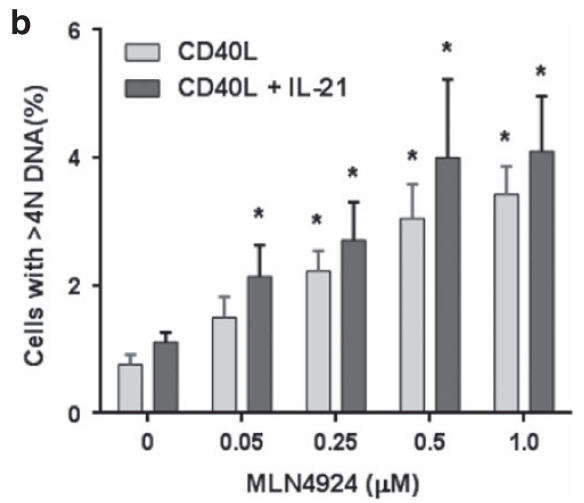

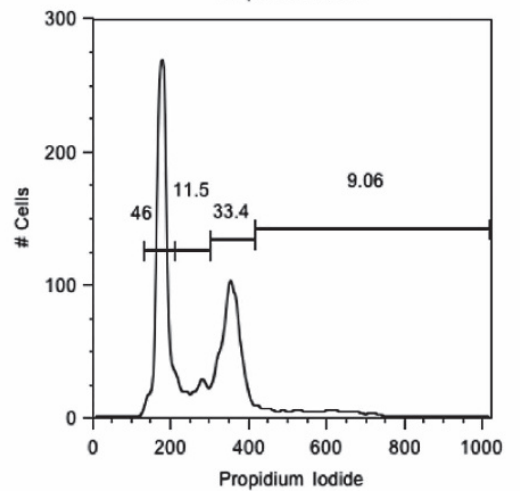

0.25

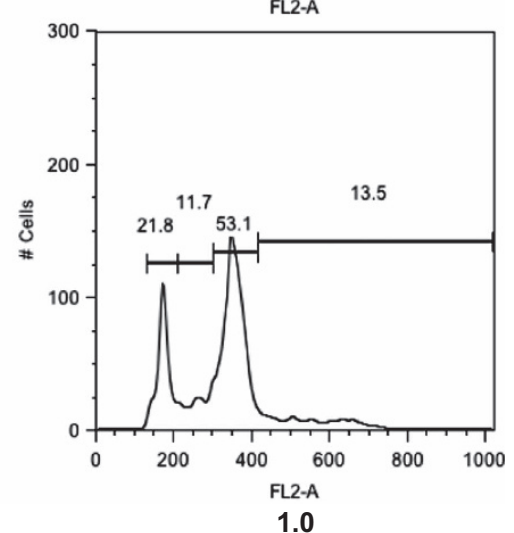

MLN4924 ( $\mu \mathrm{M})$

C

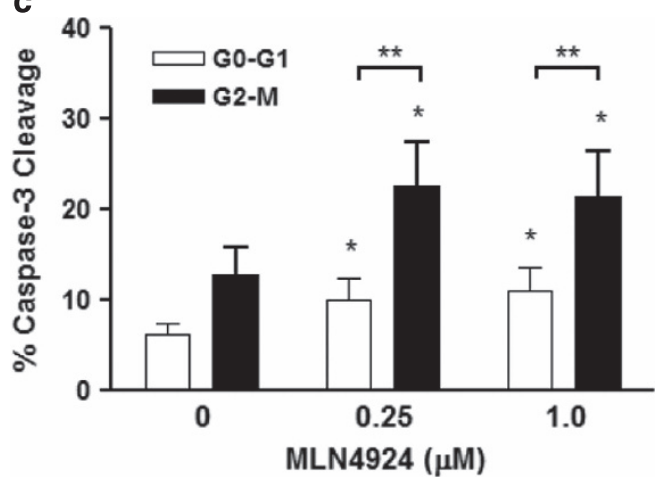


known to express high levels of BCL2 protein, and hence may be particularly sensitive to DNA damage. We therefore argue that NAE inhibition-mediated replication stress may contribute to increased apoptotic priming of the CLL cells.
Despite significant advances of targeted therapy in CLL, chemoimmunotherapy remains a mainstay of treatment in younger patients, particularly in the upfront setting. Bendamustine, a bifunctional alkylating agent, has received wide-

a

\section{CLL169}

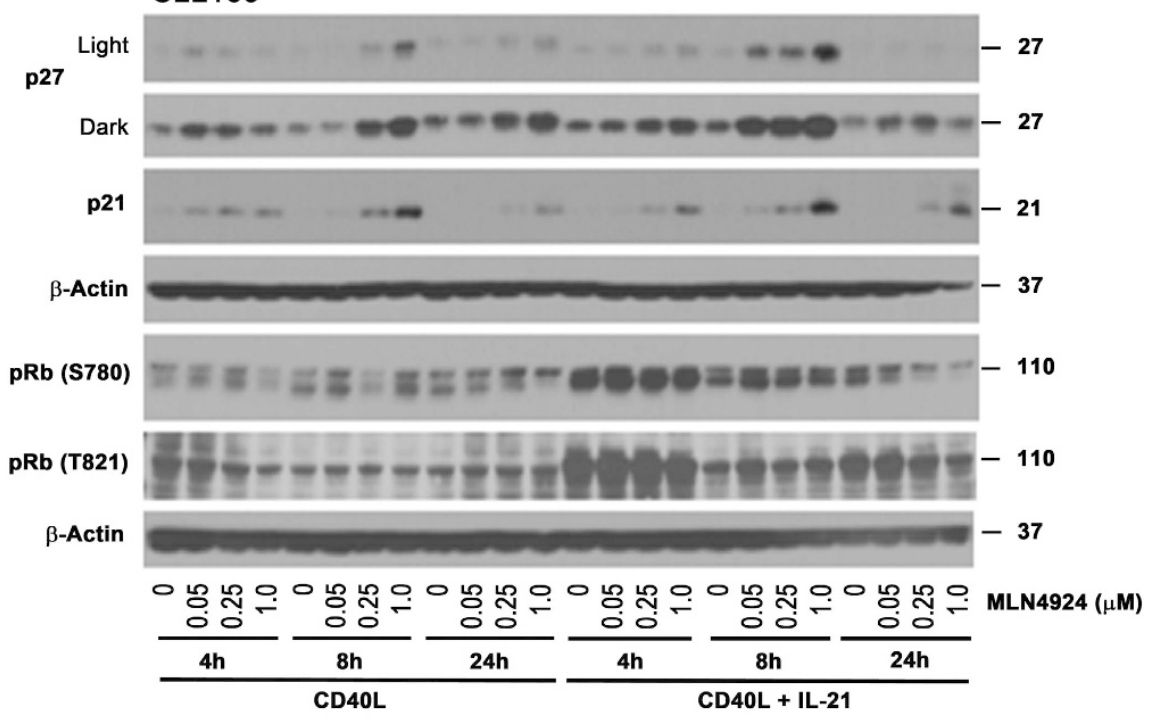

b

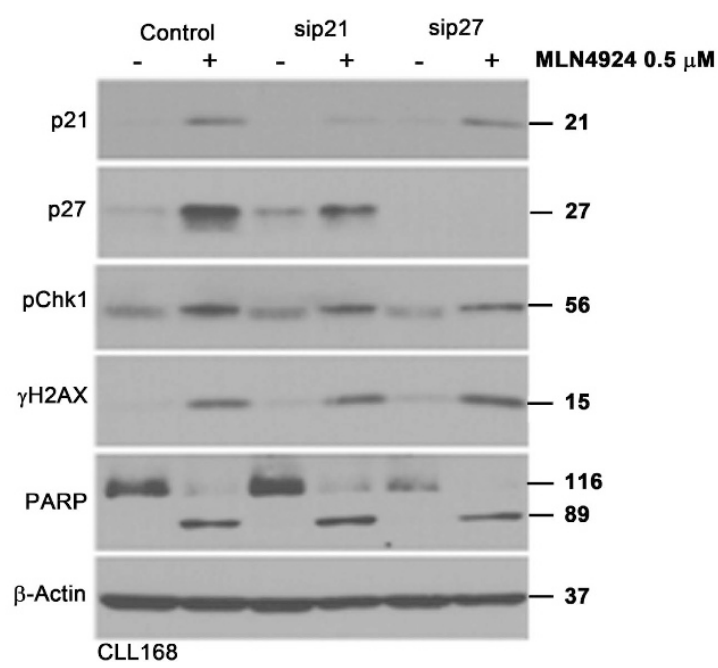

Figure 5 Effect of MLN4924 on CDK inhibitors p21 and p27 in CLL cells. (a) CLL cells were co-cultured with CD40L-expressing stroma in the presence or not of $25 \mathrm{ng} / \mathrm{ml}$ IL-21 for $72 \mathrm{~h}$. Thereafter, cells were treated with $0.05-1 \mu \mathrm{M}$ MLN4924 or vehicle control, collected at the indicated time points and subjected to immunoblotting. Images representative of at least four independent experiments are shown. (b) CLL cells were transfected with the individual siRNAs against p21, p27 or control siRNA using Amaxa

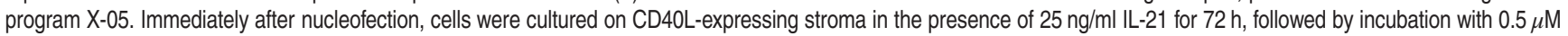
MLN4924 or vehicle control for $24 \mathrm{~h}$. Whole-cell lysates were subjected to immunoblotting. Representative blots of three independent experiments are shown

Figure 6 MLN4924 enhances activity of the alkylating agents in CLL. (a) CLL cells $(N=10)$ were co-cultured with CD40L-expressing stroma for $24 \mathrm{~h}$, followed by incubation with the indicated compounds or with vehicle control for $48 \mathrm{~h}$. Apoptosis within the CD19+ subset of cells was determined by Annexin V and 7-AAD staining. (b) $C L L$ cells $(N=8)$ were co-cultured with CD40L-expressing stroma in the presence or not of $25 \mathrm{ng} / \mathrm{ml} \mathrm{IL-21}$ for $72 \mathrm{~h}$. Thereafter, cells were treated as shown. Cells were collected at the indicated time points and assayed for apoptosis (data are mean \pm S.E.). (c) CLL cells were co-cultured with CD40L-expressing stroma for $24 \mathrm{~h}$, followed by incubation with the indicated drugs or with vehicle control for $24 \mathrm{~h}$. Cells were lysed and subjected to immunoblotting (a representative image out of four independent experiments is shown). (d) CLL cells $(\mathrm{N}=8$ ) were co-cultured with CD40L-expressing stroma in the presence or not of $25 \mathrm{ng} / \mathrm{ml} \mathrm{IL-21}$ for $72 \mathrm{~h}$. Thereafter, cells were treated with drugs alone or in combination for $24 \mathrm{~h}$ and assayed by FACS analysis for cell cycle profiling and cell population with more than 4N DNA content. (e) CLL cells were co-cultured with CD40L-expressing stroma $24 \mathrm{~h}$, treated with the indicated for $24 \mathrm{~h}$ and subjected to immunoblotting. A representative image of three independent experiments is shown. (f) Cells with del( $(17 p)(N=10)$ or not were treated with drugs as above for $48 \mathrm{~h}$ and assayed for apoptosis as above; cells without del(17p) were lysed after $24 \mathrm{~h}$ of incubation with drugs and subjected to immunoblotting. Data are mean \pm S.E. ${ }^{*} P<0.01$ and ${ }^{*} P<0.05$ compared with either single drug 
a

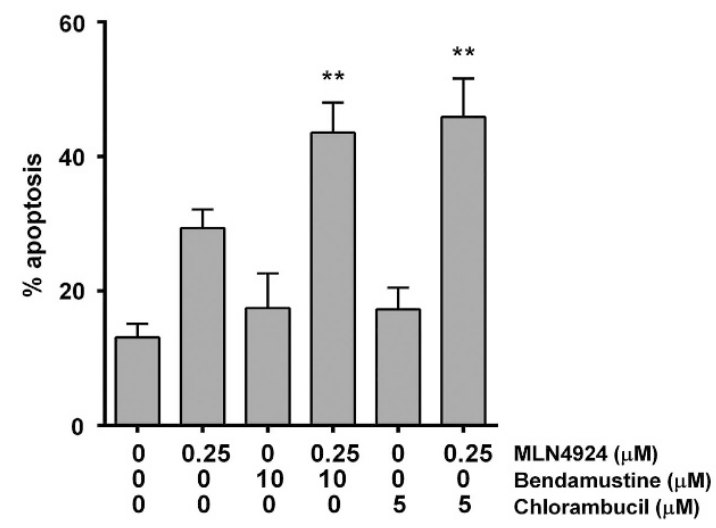

c

$-\quad+\quad-\quad+\quad \operatorname{MLN} 4924(0.25 \mu \mathrm{M})$

$-\quad-\quad+\quad+$ Bemdamustine $(1 \mu \mathrm{M})$
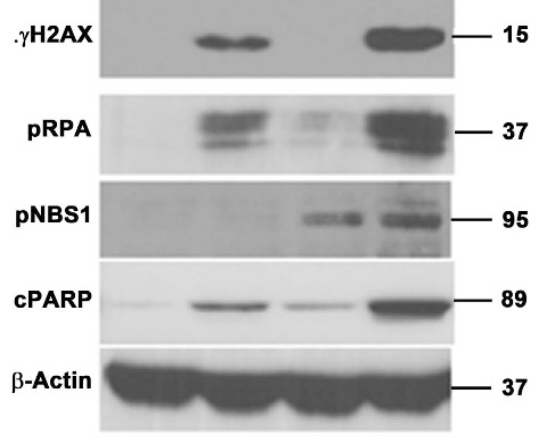

e
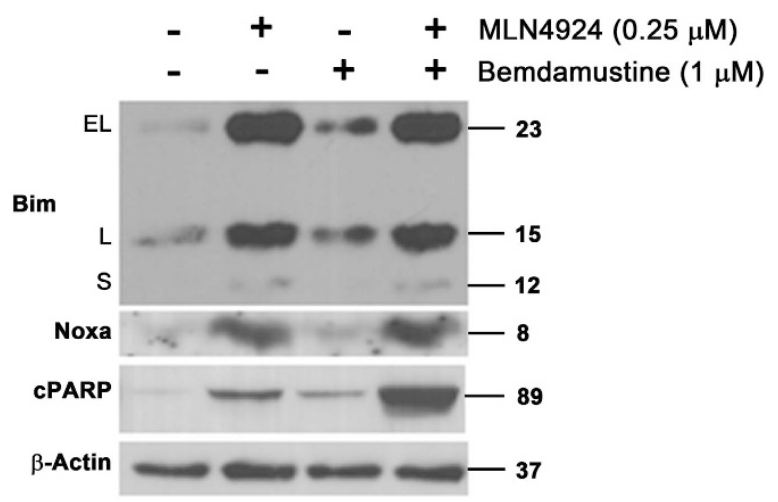

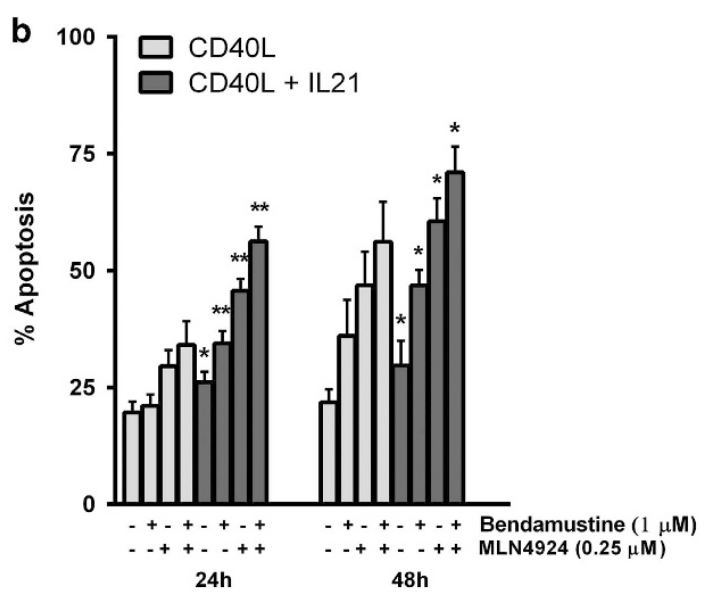

d
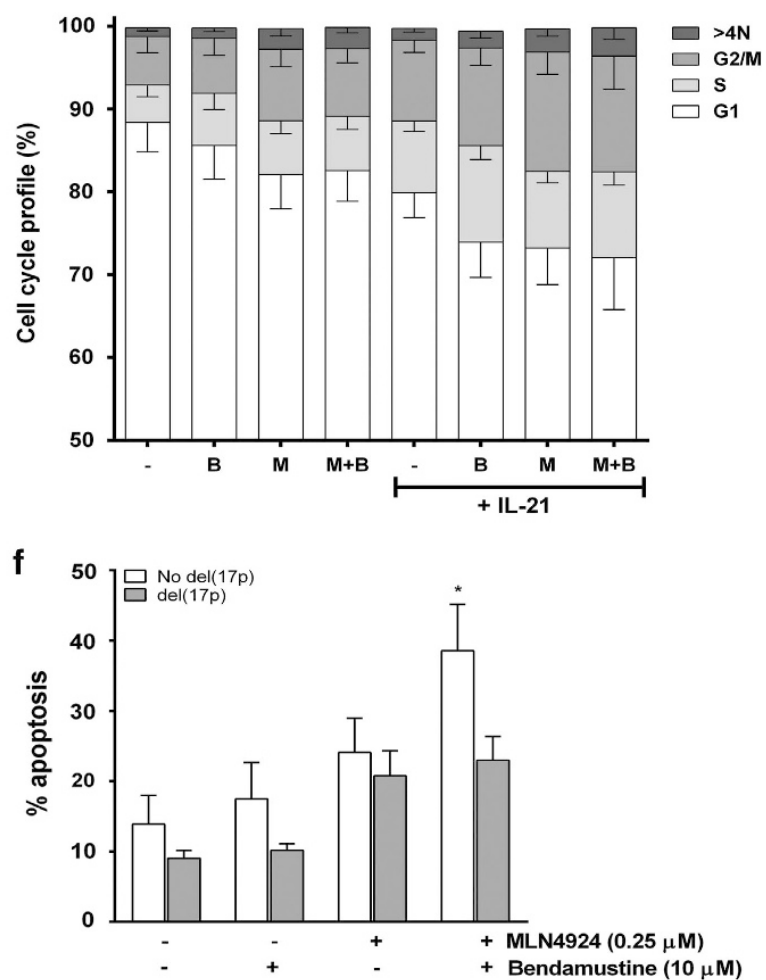

- $\quad+\quad$ - $\quad+\quad$ MLN4924 $(0.25 \mu \mathrm{M})$

$-\quad+\quad+\quad+$ Bemdamustine $(1 \mu \mathrm{M})$

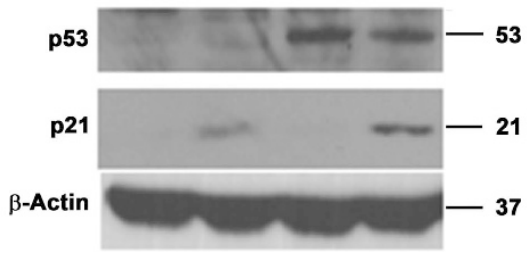


spread use in CLL. ${ }^{28,39,40}$ Bendamustine induces doublestrand DNA damage, purportedly its main mechanism of toxicity, as well as unique DNA repair responses such as base excision repair. ${ }^{25,41}$ In lymphoma cell lines, bendamustine activated p53 via elevated expression and phosphorylation at $\mathrm{S} 15,{ }^{25}$ a target site of ATM, ATR and DNA-PK. In accordance with these data, we observed phosphorylation of NBS1 (Nijmegen breakage syndrome 1) in response to bendamustine treatment in CLL cells, consistent with double-stranded DNA damage. Despite that, CLL cells were resistant to bendamustine on stroma in the absence of IL-21, indicating that sufficient DNA repair took place. However, a combination of MLN4924 and bendamustine significantly augmented the extent of double-stranded DNA damage and led to enhanced apoptosis. As bendamustine is particularly efficient in cycling cells, IL-21 co-stimulation sensitized CLL cells to the drug combination. Finally, NAE inhibition was shown to impair the DNA damage response, ${ }^{17,42}$ providing further potential explanation for the cooperative action of this drug combination in CLL. Our findings echo a recent preclinical analysis where bendamustine-induced DNA damage was enhanced because of fludarabine-mediated inhibition of DNA repair and abrogated the protective effects of stroma. ${ }^{43}$ Importantly, we show that MLN4924 in combination with bendamustine did not enhance apoptosis of the CLL cells with del(17p), suggesting that although this is a promising therapeutic strategy, it is not relevant to CLL with defective p53.

In summary, we demonstrate that targeting NAE induces DNA damage, checkpoint activation and cell cycle arrest in CLL cells. This, coupled with abrogation of the NF- $k B$ activity, results in apoptosis and reversal of stromal-mediated protection. Our study sheds light on the mechanism of action of MLN4924 in CLL and B-cell malignancies and suggests a new therapeutic strategy to enhance the efficacy of the alkylating agents.

\footnotetext{
Materials and methods

Patient samples, CLL and stromal cell co-cultures. Peripheral blood was obtained from patients with B-CLL at Dartmouth-Hitchcock Medical Center and Oregon Health and Science University following approval by the respective institutional review board and written informed consent of patients, the majority of whom were previously untreated. Blood was also obtained from six healthy volunteers. Isolation of peripheral blood mononuclear cells (PBMCs) was performed using standard Ficoll-Hypaque techniques (Amersham, Piscataway, NJ, USA). Such $\mathrm{CLL}$ samples had $>90 \% \mathrm{CDF}^{+} / \mathrm{CD} 19^{+}$cells, as determined by flow cytometry. CLL cells were cultured in RMPI-1640 supplemented with $15 \%$ fetal bovine serum, $100 \mathrm{U} / \mathrm{ml}$ penicillin, $100 \mu \mathrm{g} / \mathrm{ml}$ streptomycin, $2 \mathrm{mM}$ L-glutamine, $25 \mathrm{mM}$ HEPES, $100 \mu \mathrm{M}$ non-essential amino acids and $1 \mathrm{mM}$ sodium pyruvate (Lonza, Walkersville, MD, USA). Ten CLL samples with 17p deletion were obtained from the CLL Center at Dana-Farber Cancer Institute. All experiments were performed with freshly isolated CLL cells except the viability assays involving the latter that were performed with viably frozen cells.

The mouse fibroblast cell line ( $L$ cells) engineered to express CD40L ( $L 4.5)$ was given to us by Dr. Sonia Neron (Université Laval, Laval, QC, Canada) ${ }^{44}$ and were maintained in RPMI-1640 medium with 10\% FBS and penicillin-streptomycin. CLL cells were cultured under standardized conditions on stromal cells as previously described. ${ }^{4}$ Briefly, stromal cells were seeded to achieve $80-100 \%$ confluence; on the following day, CLL cells were plated at a $50: 1$ ratio and incubated at $37^{\circ} \mathrm{C}$ in $5 \%$ $\mathrm{CO}_{2}$. To induce proliferation, CLL cells were stimulated with $25 \mathrm{ng} / \mathrm{ml} \mathrm{IL}-21$ (Cell Signaling, Danvers, MA, USA) or $1.5 \mu \mathrm{M} \mathrm{CpG-ODN} \mathrm{(a} \mathrm{kind} \mathrm{gift} \mathrm{from} \mathrm{Dr.} \mathrm{John}$ Byrd, Ohio State University, Columbus, OH, USA) for $72 \mathrm{~h}$, treated with drugs thereafter and assayed for apoptosis, cell cycle distribution or immunoblotting as detailed below. At harvest, CLL cells were gently washed off the stromal layer. When
}

collected for protein analysis, CLL cells were transferred to a new plate and incubated for an additional 60 min to allow reattachment of stromal cells and thus minimize contamination of CLL cells. Where indicated, cells were also cultured off stroma at the same density.

Cell viability testing and drugs. CLL cell apoptosis was measured in duplicate as previously described using the ApoScreen Annexin V Apoptosis Kit. ${ }^{45}$ Briefly, cells were resuspended in $150 \mu \mathrm{l}$ of Annexin V binding buffer containing $1 \mu \mathrm{l}$ of Annexin V-PE, $1 \mu \mathrm{l}$ of 7-aminoactinomycin (7-AAD) and $1 \mu \mathrm{l}$ of CD19-FITC (Southern Biotech, Birmingham, AL, USA) and CD3-APC antibodies (Miltenyi Biotec, San Diego, CA, USA), followed by flow cytometry on a MACSQuant (Miltenyi Biotec). The following drugs were used: MLN4924 (provided by Millennium Pharmaceuticals Inc., Cambridge, MA, USA), bendamustine, BMS-345541 (SigmaAldrich, St. Louis, MO, USA) and chlorambucil (MP Biomedicals, Solon, OH, USA).

Immunoblotting. Cells were lysed in RIPA buffer $(20 \mathrm{mM}$ Tris, $150 \mathrm{mM} \mathrm{NaCl}$, 1\% NP-40, $1 \mathrm{mM} \mathrm{NaF}, 1 \mathrm{mM}$ sodium phosphate, $1 \mathrm{mM}$ NaVO3, $1 \mathrm{mM}$ EDTA, $1 \mathrm{mM}$ EGTA, supplemented with protease inhibitor cocktail (Roche, Indianapolis, IN, USA), phosphatase inhibitor cocktail 2 (Sigma-Aldrich) and $1 \mathrm{mM}$ phenylmethanesulfonyl fluoride). Proteins were analyzed by immunoblotting as previously described. ${ }^{45}$ The following antibodies were used: Bim, CDC25A, Chk1, phospho-Chk1 (S345), $\gamma \mathrm{H} 2 \mathrm{AX}$ (S139), PARP and cleaved PARP, p21, p53, phospho-p95/NBS1 (S343), Rb (S780), Wee1 (all from Cell Signaling); Cdt1 (F-6), p27 (C-19), total Rb (C-15; Santa Cruz Biotechnology, Santa Cruz, CA, USA), NOXA (Imgenex, San Diego, CA, USA), Rb (T821; Life Technologies, Carlsbad, CA, USA), $\beta$-actin (Sigma-Aldrich), phosphoRPA32 (S4/S8) (Bethyl, Montgomery, TX, USA) and horseradish peroxidaseconjugated anti-mouse and anti-rabbit antibodies (Bio-Rad, Hercules, CA, USA).

Immunocytochemistry. $3 \times 10^{5}$ cells were adhered onto polylysine D-coated coverslips (Sigma-Aldrich) during a $45-$ min incubation at $37^{\circ} \mathrm{C}$, fixed in $10 \%$ formalin (Fisher Scientific, Pittsburgh, PA, USA) and permeabilized in 1\% Triton-X 100 in PBS. Coverslips were blocked for $30 \mathrm{~min}$ in $5 \%$ bovine serum albumin (Sigma-Aldrich) in PBS with $0.1 \%$ Tween-20, probed with $\gamma \mathrm{H}_{2} \mathrm{AX}$ (S139), phospho-RPA32 (S4/S8) or Ki67 antibodies (conjugated with AlexaFluor647; Life Technologies) and then with DyLight 488 goat anti-rabbit antibodies (Thermo Scientific, Carlsbad, CA, USA). Coverslips were mounted with anti-fading ProLong Gold Solution (Life Technologies) with 4',6diamidino-2-phenylindole (DAPI, for nuclear counterstaining). Fluorescent images were captured with a Zeiss AxioCam MRm camera mounted on a Zeiss Observer.Z1 microscope (Zeiss, Jena, Germany). Cells positive for $\gamma \mathrm{H}_{2} \mathrm{AX}$ or phospho-RPA were counted in six high-power fields per condition ( $\times 20$ magnification) and referenced to the total number of cells quantified using ImageJ software (National Institutes of Health, Bethesda, MD, USA).

siRNA-mediated gene silencing. Electroporation of siRNA into CLL cells was performed using Amaxa Human B-cell Nucleofection Kit (Amaxa, Cologne, Germany) as previously described. ${ }^{45}$ Briefly, $1 \times 10^{7}$ PBMCs were mixed with $100 \mu$ l of Amaxa B-cell nucleofector solution, and $2 \mu \mathrm{g}$ of siRNA was nucleofected using program X-05. This resulted in transfection efficiency of 30-60\% (as determined with $2 \mu \mathrm{g}$ pMaxGFP plasmid) and viability of $50-80 \%$ cells at $24 \mathrm{~h}$. The following siRNA sequences were used (sense strand): Cdt1, 5'-GCAAUGUUGGCCAGA UCAA-3'; p27, 5'-GCAACCGACGAUUCUUCUACUCA-3'; p21, 5'-CUGUACUGUU CUGUGUCUU-3' (all from Dharmacon, Lafayette, CO, USA).

Cell cycle analysis. $2 \times 10^{5}$ cells were fixed in ice-cold $70 \%$ ethanol while being vortexed, incubated on ice for $15 \mathrm{~min}$, washed in PBS and resuspended in $250 \mu$ l of staining solution containing $20 \mathrm{ng} / \mathrm{ml}$ propidium iodide, $200 \mathrm{ng} / \mathrm{ml}$ RNAse A (Sigma-Aldrich), $0.1 \%$ Triton-X 100 and $1 \mu \mathrm{l}$ CD19-FITC mAb in PBS. Cells were incubated for $15 \mathrm{~min}$ and submitted to flow cytometry. For concurrent cell cycle and apoptosis staining, $5 \times 10^{6}$ cells were fixed and permeabilized using the Inside Stain Kit (Miltenyi Biotec) according to the manufacturer's instructions. Staining solution contained $20 \mathrm{ng} / \mathrm{ml}$ propidium iodide, $200 \mathrm{ng} / \mathrm{ml}$ RNAse A, $1 \mu \mathrm{l}$ anti-cleaved caspase-3 antibody (Cell Signaling) and $1 \mu$ l DyLight-488 goat anti-mouse secondary antibody (Thermo Scientific). Cell cycle analysis was performed using FlowJo software (Tree Star, Ashland, OR, USA).

5-ethynyl-2'-deoxyuridine (EdU) incorporation analysis. At $2 \mathrm{~h}$ before collection, cells were treated with EdU, a thymine analog, to allow for incorporation in replicating cells. Cells were then collected, washed with PBS, fixed in $2 \%$ paraformaldehyde and stored at $4{ }^{\circ} \mathrm{C}$ until analysis. Subsequently, cells were 
processed using Click-iT EdU AlexaFluor 647 Assay Kit (Life Technologies) according to the manufacturer's instruction, and subjected to flow cytometry Analysis was performed using the FlowJo software.

Statistical analysis. Results of individual experiments were analyzed using paired and unpaired Student's t-test, Fisher's exact test, nonparametric Mann-Whitney test and Spearman's $r$. Statistical analyses were completed using the GraphPad Prism 6 software package (La Jolla, CA, USA). All tests were two sided, and data were considered to be statistically significant at $P<0.05$

\section{Conflict of Interest}

Allison Berger is an employee of Millennium Pharmaceuticals, Inc., a wholly owned subsidiary of Takeda Pharmaceutical Company, Ltd.

Acknowledgements. We thank Drs. Eric Lightcap, Christopher Danes and Alan Eastman for their very helpful review of this manuscript. This work was supported by the Lymphoma Research Foundation Clinical Investigator Career Development Award to AVD. JRB is supported by the Leukemia Lymphoma Society and the American Cancer Society and is a Scholar in Clinical Research of the Leukemia and Lymphoma Society.

\section{Author contributions}

AVD is the principal investigator and takes primary responsibility for the paper. AVD, $J C G$ and $C P$ designed research. CP and JCG performed experiments. CP, JCG and $A V D$ analyzed data. JRB and $A B$ contributed vital reagents. All authors wrote the paper.

1. Pan ZQ, Kentsis A, Dias DC, Yamoah K, Wu K. Nedd8 on cullin: building an expressway to protein destruction. Oncogene 2004; 23: 1985-1997.

2. Burger JA, Ghia $P$, Rosenwald A, Caligaris-Cappio $F$. The microenvironment in mature B-cell malignancies: a target for new treatment strategies. Blood 2009; 114 3367-3375.

3. Herishanu Y, Perez-Galan P, Liu D, Biancotto A, Pittaluga S, Vire B et al. The lymph node microenvironment promotes B-cell receptor signaling, NF-kappaB activation, and tumo proliferation in chronic lymphocytic leukemia. Blood 2011; 117: 563-574.

4. Godbersen JC, Humphries LA, Danilova OV, Kebbekus PE, Brown JR, Eastman A et al. The Nedd8-activating enzyme inhibitor MLN4924 thwarts microenvironment-driven NF-kappaB activation and induces apoptosis in chronic lymphocytic leukemia B cells. Clin Cancer Res 2014; 20: 1576-1589.

5. Petroski MD, Deshaies RJ. Function and regulation of cullin-RING ubiquitin ligases. Nat Rev Mol Cell Biol 2005; 6: 9-20.

6. Brownell JE, Sintchak MD, Gavin JM, Liao H, Bruzzese FJ, Bump NJ et al. Substrateassisted inhibition of ubiquitin-like protein-activating enzymes: the NEDD8 E1 inhibitor MLN4924 forms a NEDD8-AMP mimetic in situ. Mol Cell 2010; 37: 102-111.

7. Soucy TA, Smith PG, Milhollen MA, Berger AJ, Gavin JM, Adhikari S et al. An inhibitor of NEDD8-activating enzyme as a new approach to treat cancer. Nature 2009; 458 732-736.

8. Milhollen MA, Traore T, Adams-Duffy J, Thomas MP, Berger AJ, Dang L et al. MLN4924, a NEDD8-activating enzyme inhibitor, is active in diffuse large B-cell lymphoma models: rationale for treatment of NF-\{kappa\}B-dependent lymphoma. Blood 2010; 116: 1515-1523.

9. Wei D, Li H, Yu J, Sebolt JT, Zhao L, Lawrence TS et al. Radiosensitization of human pancreatic cancer cells by MLN4924, an investigational NEDD8-activating enzyme inhibitor. Cancer Res 2012; 72: 282-293.

10. Zhao $Y$, Xiong X, Jia L, Sun Y. Targeting Cullin-RING ligases by MLN4924 induces autophagy via modulating the HIF1-REDD1-TSC1-mTORC1-DEPTOR axis. Cell Death Dis 2012; 3: e386

11. Yang $D$, Tan $M$, Wang $G$, Sun $Y$. The p21-dependent radiosensitization of human breas cancer cells by MLN4924, an investigational inhibitor of NEDD8 activating enzyme. PLoS One 2012; 7: e34079.

12. Nakayama KI, Nakayama K. Ubiquitin ligases: cell-cycle control and cancer. Nat Rev Cance 2006; 6: 369-381.

13. Dengler MA, Weilbacher A, Gutekunst M, Staiger AM, Vohringer MC, Horn $\mathrm{H}$ et al. Discrepant NOXA (PMAIP1) transcript and NOXA protein levels: a potential Achilles' heel in mantle cell lymphoma. Cell Death Dis 2014; 5: e1013.

14. Lee J, Zhou P. Cullins and cancer. Genes Cancer 2010; 1: 690-699.

15. Lin JJ, Milhollen MA, Smith PG, Narayanan U, Dutta A. NEDD8-targeting drug MLN4924 elicits DNA rereplication by stabilizing Cdt1 in S phase, triggering checkpoint activation, apoptosis, and senescence in cancer cells. Cancer Res 2010; 70: 10310-10320.
16. Milhollen MA, Narayanan U, Soucy TA, Veiby PO, Smith PG, Amidon B. Inhibition of NEDD8activating enzyme induces rereplication and apoptosis in human tumor cells consistent with deregulating CDT1 turnover. Cancer Res 2011; 71: 3042-3051.

17. Blank JL, Liu XJ, Cosmopoulos K, Bouck DC, Garcia K, Bernard H et al. Novel DNA damage checkpoints mediating cell death induced by the NEDD8-activating enzyme inhibitor MLN4924. Cancer Res 2013; 73: 225-234.

18. Davids MS, Deng J, Wiestner A, Lannutti BJ, Wang L, Wu CJ et al. Decreased mitochondrial apoptotic priming underlies stroma-mediated treatment resistance in chronic lymphocytic leukemia. Blood 2012; 120: 3501-3509.

19. Tromp JM, Tonino SH, Elias JA, Jaspers A, Luijks DM, Kater AP et al. Dichotomy in NF-kappaB signaling and chemoresistance in immunoglobulin variable heavy-chainmutated versus unmutated CLL cells upon CD40/TLR9 triggering. Oncogene 2010; 29: 5071-5082.

20. Gowda A, Roda J, Hussain SR, Ramanunni A, Joshi T, Schmidt S et al. IL-21 mediates apoptosis through up-regulation of the $\mathrm{BH} 3$ family member BIM and enhances both direct and antibody-dependent cellular cytotoxicity in primary chronic lymphocytic leukemia cells in vitro. Blood 2008; 111: 4723-4730.

21. Pascutti MF, Jak M, Tromp JM, Derks IA, Remmerswaal EB, Thijssen R et al. IL-21 and $\mathrm{CD} 40 \mathrm{~L}$ signals from autologous $\mathrm{T}$ cells can induce antigen-independent proliferation of CLL cells. Blood 2013; 122: 3010-3019.

22. Davidson IF, Li A, Blow JJ. Deregulated replication licensing causes DNA fragmentation consistent with head-to-tail fork collision. Mol Cell 2006; 24: 433-443.

23. Mackintosh C, Garcia-Dominguez DJ, Ordonez JL, Ginel-Picardo A, Smith PG, Sacristan MP et al. WEE1 accumulation and deregulation of S-phase proteins mediate MLN4924 potent inhibitory effect on Ewing sarcoma cells. Oncogene 2013; 32: 1441-1451.

24. Bunz F, Dutriaux A, Lengauer C, Waldman T, Zhou S, Brown JP et al. Requirement for p53 and p21 to sustain G2 arrest after DNA damage. Science 1998; 282: 1497-1501.

25. Leoni LM, Bailey B, Reifert J, Bendall HH, Zeller RW, Corbeil J et al. Bendamustine (Treanda) displays a distinct pattern of cytotoxicity and unique mechanistic features compared with other alkylating agents. Clin Cancer Res 2008; 14: 309-317.

26. Shindiapina P, Brown JR, Danilov AV. A new hope: novel therapeutic approaches to treatment of chronic lymphocytic leukaemia with defects in TP53. Br J Haematol 2014; 167: 149-161.

27. Roue G, Lopez-Guerra M, Milpied P, Perez-Galan P, Villamor N, Montserrat E et al. Bendamustine is effective in p53-deficient B-cell neoplasms and requires oxidative stress and caspase-independent signaling. Clin Cancer Res 2008; 14: 6907-6915.

28. Fischer K, Cramer P, Busch R, Stilgenbauer S, Bahlo J, Schweighofer CD et al. Bendamustine combined with rituximab in patients with relapsed and/or refractory chronic Iymphocytic leukemia: a multicenter phase II trial of the German Chronic Lymphocytic Leukemia Study Group. J Clin Oncol 2011; 29: 3559-3566.

29. Danilov AV, Soderquist RS, Bates DJ, Eastman A. Toward a cure for chronic Iymphocytic leukemia: an attack on multiple fronts. Expert Rev Anticancer Ther 2013; 13: 1009-1012.

30. Endo T, Nishio M, Enzler T, Cottam HB, Fukuda T, James DF et al. BAFF and APRIL support chronic lymphocytic leukemia B-cell survival through activation of the canonical NF-kappaB pathway. Blood 2007; 109: 703-710.

31. Rickert RC, Jellusova J, Miletic AV. Signaling by the tumor necrosis factor receptor superfamily in B-cell biology and disease. Immunol Rev 2011; 244: 115-133.

32. Damle RN, Temburni S, Calissano C, Yancopoulos S, Banapour T, Sison C et al. CD38 expression labels an activated subset within chronic lymphocytic leukemia clones enriched in proliferating B cells. Blood 2007; 110: 3352-3359

33. Messmer BT, Messmer D, Allen SL, Kolitz JE, Kudalkar P, Cesar D et al. In vivo measurements document the dynamic cellular kinetics of chronic lymphocytic leukemia B cells. J Clin Invest 2005; 115: 755-764.

34. Jin J, Arias EE, Chen J, Harper JW, Walter JC. A family of diverse Cul4-Ddb1-interacting proteins includes $\mathrm{Cdt} 2$, which is required for $\mathrm{S}$ phase destruction of the replication factor Cdt1. Mol Cell 2006; 23: 709-721.

35. Klotz-Noack K, Mclntosh D, Schurch N, Pratt N, Blow JJ. Re-replication induced by geminin depletion occurs from G2 and is enhanced by checkpoint activation. J Cell Sci 2012; 125: 2436-2445.

36. Muller MR, Buschfort C, Thomale J, Lensing C, Rajewsky MF, Seeber S. DNA repair and cellular resistance to alkylating agents in chronic lymphocytic leukemia. Clin Cancer Res 1997; 3: 2055-2061.

37. Buschfort C, Muller MR, Seeber S, Rajewsky MF, Thomale J. DNA excision repair profiles of normal and leukemic human lymphocytes: functional analysis at the single-cell level. Cancer Res 1997; 57: 651-658.

38. Xie M, Yen Y, Owonikoko TK, Ramalingam SS, Khuri FR, Curran WJ et al. Bcl2 induces DNA replication stress by inhibiting ribonucleotide reductase. Cancer Res 2014; 74: 212-223.

39. Fischer K, Cramer P, Busch R, Bottcher S, Bahlo J, Schubert J et al. Bendamustine in combination with rituximab for previously untreated patients with chronic lymphocytic leukemia: a multicenter phase II trial of the German Chronic Lymphocytic Leukemia Study Group. J Clin Oncol 2012; 30: 3209-3216.

40. Cheson BD, Rummel MJ. Bendamustine: rebirth of an old drug. J Clin Oncol 2009; 27: 1492-1501.

41. Strumberg D, Harstrick A, Doll K, Hoffmann B, Seeber S. Bendamustine hydrochloride activity against doxorubicin-resistant human breast carcinoma cell lines. Anticancer Drugs 1996; 7: 415-421. 
42. Kee Y, Huang M, Chang S, Moreau LA, Park E, Smith PG et al. Inhibition of the Nedd8 system sensitizes cells to DNA interstrand cross-linking agents. Mol Cancer Res 2012; 10: 369-377.

43. El-Mabhouh AA, Ayres ML, Shpall EJ, Baladandayuthapani V, Keating MJ, Wierda WG et al. Evaluation of bendamustine in combination with fludarabine in primary chronic lymphocytic leukemia cells. Blood 2014; 123: 3780-3789.

44. Neron S, Suck G, Ma XZ, Sakac D, Roy A, Katsman $Y$ et al. B cell proliferation following CD40 stimulation results in the expression and activation of Src protein tyrosine kinase. Int Immunol 2006; 18: 375-387.

45. Humphries LA, Godbersen JC, Danilova OV, Kaur P, Christensen BC, Danilov AV. Pro-apoptotic TP53 homolog TAp63 is repressed via epigenetic silencing and B-cell receptor signalling in chronic lymphocytic leukaemia. Br J Haematol 2013; 163: 590-602.
Cell Death and Disease is an open-access journal published by Nature Publishing Group. This work is licensed under a Creative Commons Attribution 4.0 International License. The images or other third party material in this article are included in the article's Creative Commons license, unless indicated otherwise in the credit line; if the material is not included under the Creative Commons license, users will need to obtain permission from the license holder to reproduce the material. To view a copy of this license, visit http://creativecommons.org/licenses/by/4.0/

Supplementary Information accompanies this paper on Cell Death and Disease website (http://www.nature.com/cddis) 